Pacific Journal of Mathematics

AN UNEXPECTED SURGERY CONSTRUCTION OF A LENS

James Bailey and Dale Rolfsen 


\section{AN UNEXPECTED SURGERY CONSTRUCTION OF A LENS SPACE}

\section{James Bailey and Dale Rolfsen}

A useful method of constructing-3-dimensional manifolds is to remove the interior of a tubular neighbourhood $V \subset S^{3}$ of a knot $K$ in the 3-sphere and sew it back differently, via a homeomorphism $h: \partial V \rightarrow \partial V$. This surgery construction, due to $M$. Dehn, yields the manifold

$$
M^{3}=\left(S^{3}-\operatorname{int} V\right) \bigcup_{h} V,
$$

where $x \in \partial V \subset V$ is identified with $h(x) \in \partial V \subset S^{3}-\operatorname{int} V$. For example surgery along a trivial knot yields, for various choices of $h$, exactly the class of lens spaces $L(p, q)$, including the extreme cases $L(1,0) \cong S^{3}$ and $L(0,1) \cong S^{2} \times S^{1}$.

Louise Moser has shown in [3] that certain surgeries along nontrivial torus knots also yield lens spaces. Strong circumstantial evidence led her to conjecture a converse.

Moser's conjecture. If $M^{3}$ is a lens space obtained by surgery along $K$, then $K$ is a torus knot.

The purpose of this paper is to present a counterexample to this conjecture (it is also a counterexample to the other two conjectures of [3]). This conjecture also has been put forward by J. P. Neuzil [4].

THEOREM. The lens space $L(23,7)$ is the result of an appropriate surgery along the knot of Figure 1, which is not a torus knot.

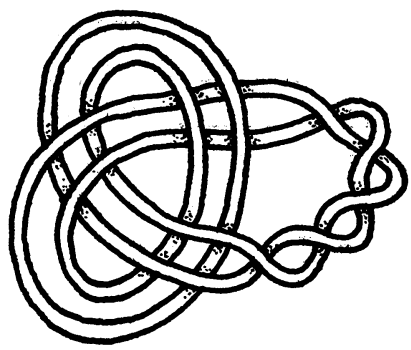

Figure 1

To explain the proof, some notational conventions need to be stated. Suppose $K$ is a tame knot in $S^{3}$ and $V$ is a solid torus neighbourhood of $K$. Assume for the moment that $K$ is oriented. 
A preferred longitude is an oriented curve $\lambda$ in $\partial V$ which is homotopic in $V$ to the centerline $K$ and has linking number zero with $K$. A preferred meridian is an oriented curve $\mu$ in $\partial V$ which is homotopically trivial in $V$ and links $K$ once in, say, a right-hand screw sense. Their homology classes, which we also denote by $\lambda$ and $\mu$, form a distinguished basis for $H_{1}(\partial V) \cong Z \oplus Z$. Any oriented simple closed curve in $\partial V$ has homology class $l \lambda+m \mu$, where $l$ and $m$ are relatively prime integers. To designate the manifold obtained by removing the interior of $V$ from $S^{3}$ and replacing it via a homeomorphism $h: \partial V \rightarrow \partial V$ we need only specify the knot $K$ and the ratio

$$
r=m / l \quad \text { where } \quad h_{*}(\mu)=l \lambda+m \mu .
$$

The possibility $r= \pm 1 / 0=\infty$ is allowed, corresponding to the "trivial" surgery in which $V$ is replaced using the identity map on the boundary. The choice of orientation of $K$ is irrelevant to this definition of $r$, which well call the surgery coefficient assigned to $K$. More generally one can specify a 3-manifold, well-determined up to homeomorphism, by choosing a tame link $L=L_{1} \cup \cdots \cup L_{n}$ in $S^{3}$ and surgery coefficients $r_{1}, \cdots, r_{n}$ which describe, as above, how to remove and replace disjoint tubular neighbourhoods of the components of $L$. According to [2], all closed, connected, orientable 3 -manifolds arise in this manner, even if one requires each $r_{i}$ to be \pm 1 .

As an example, the lens space $L(p, q)$ is the result of surgery on a single unknotted curve using coefficient $p / q$.

The proof also employs a trick whereby a given surgery description in $S^{3}$ may be transformed into another surgery description which yields the same 3-manifold. Locate an unknotted component $L_{i}$ of the surgery link $L$. The complement of an open tubular neighbourhood of $L_{i}$ is therefore a solid torus. Give this complementary solid torus a twist so that the meridian $\mu_{i}$ of $V_{i}$ is carried to a curve of type $\tau \lambda_{i}+\mu_{i}$. The integer $\tau$ describes the number of complete twists, and is positive or negative according as the twist is in a right-or left-handed sense. This changes, in general, the other components of $L$, forming (with $L_{i}$ ) a new link $L^{\prime}$. Figure 2 illustrates the case $\tau=1$. This twist also changes the appropriate surgery coefficients (so that $L^{\prime}$ yields the same 3-manifold) according to the formulas (derived in [6]):

$$
\begin{aligned}
r_{i}^{\prime} & =\frac{1}{\tau+\frac{1}{r_{i}}} \\
r_{j}^{\prime} & =r_{j}+\tau\left(l k\left(L_{j}, L_{i}\right)\right)^{2} \text { if } j \neq i .
\end{aligned}
$$


These formulas are consistent with the conventions $1 / 0=\infty, 1 / \infty=0$, etc. Another trick which is used is that, of course, any component of a surgery description link which has a coefficient $\infty$ may simply be erased without changing the homeomorphism type of the 3-manifold thus described.

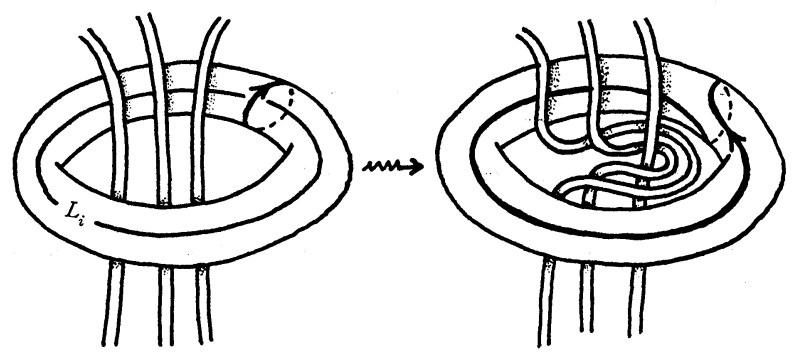

FIGURe 2. Twisting the complement of an unknotted component $L_{i}$ of $L$.

Proof of the theorem. The "appropriate" surgery is that corresponding to the surgery coefficient -23 . The bulk of the proof is contained in Figure 3. Each of the six surgery descriptions yields the same 3-manifold, according to the discussion above. The knot
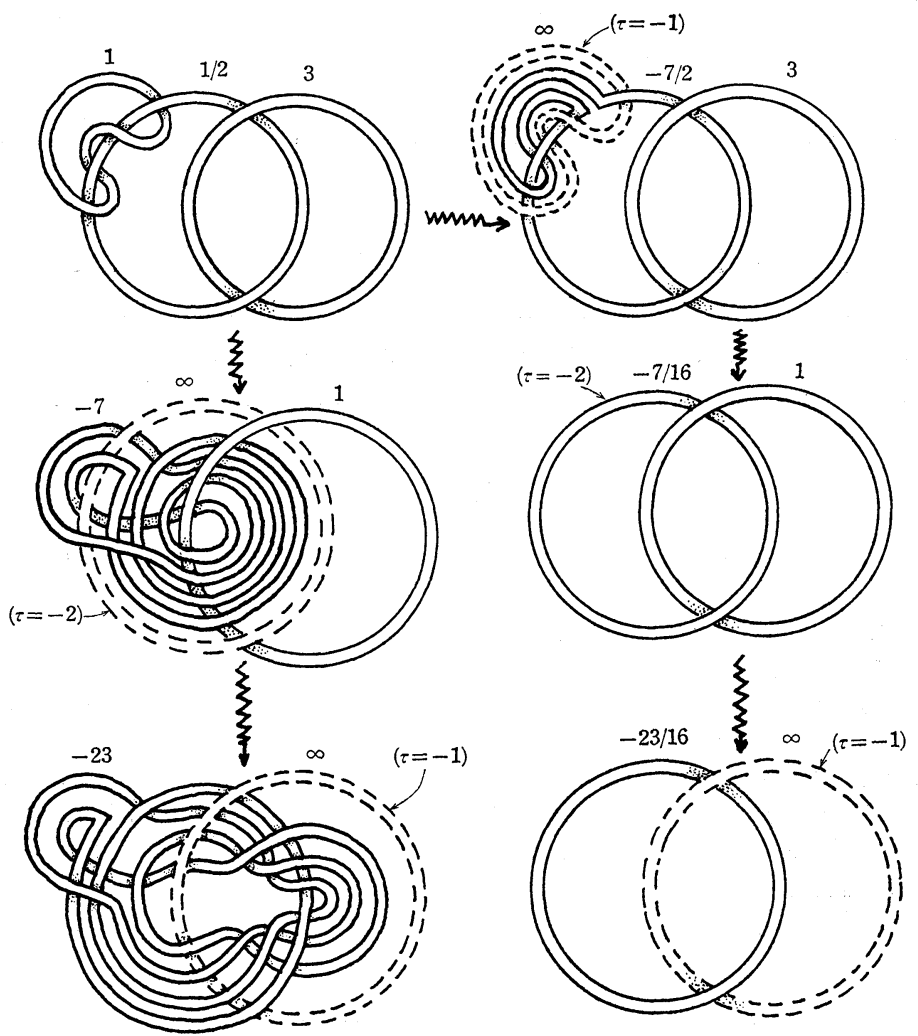

FiguRe 3 
at lower left is the same as the knot of Figure 1. The surgery description at lower right shows that the 3-manifold in question is a lens space of type $L(-23,16)$, which is homeomorphic with $L(23$, 7). Finally, the knot of Figure 1 is not a torus knot. An easy way to see this is to calculate its Alexander polynomial. Since it is an 11, 2 cable on a trefoil, we calculate by the method of [7]:

$$
\begin{aligned}
\Delta(t) & =\frac{\left(t^{22}-1\right)(t-1)}{\left(t^{11}-1\right)\left(t^{2}-1\right)}\left(t^{4}-t^{2}+1\right) \\
& =t^{14}-t^{13}+t^{10}-t^{9}+t^{8}-t^{7}+t^{6}-t^{5}+t^{4}-t+1 .
\end{aligned}
$$

Since this is not of the form $\left(t^{p q}-1\right)(t-1) /\left(t^{p}-1\right)\left(t^{q}-1\right)$, it is not a torus knot (cf. [1]).

REMARK. The referee has kindly pointed out an interesting connection between our example and recent work of J. P. Neuzil [5]. He states:

COROLlaRY 2. If $K$ is a knot in $S^{3}$ with polynomial $\Delta(t)=a_{0}+$ $\cdots+a_{p} t^{p}$ and $|\alpha|=\left|a_{0}+a_{2}+\cdots\right|>1$, then $\pi_{1}\left(M^{3}\right)$ is never $a$ finite cyclic group of even order (where $M$ denotes any manifold obtained from $S^{3}$ by surgery along $K$ ).

In our example, $\alpha=6$ and $\pi_{1}\left(M^{3}\right)$ is a finite cyclic group of order 23.

Added in proof. Jon Simon has also recently discovered our example using different methods, which show that lens spaces arise from surgery on certain iterated cable knots. Can one construct a lens space from a knot which is not a cable of a cable of ... etc.?

\section{REFERENCES}

1. W. Burau, Kennzeichnung der Schlauchknoten, Hamburger Abh., 36 (1932), 125133.

2. W. B. R. Lickorish, A representation of orientable combinatorial 3-manifolds, Ann. of Math., (2) 76 (1962), 531-540.

3. L. Moser, Elementary surgery along a torus knot, Pacific, J. Math., 38 (1971), 737-745.

4. J. P. Neuzil, Elementary surgery manifolds and elementary ideals $I$, to appear.

5. - Elementary surgery manifolds and elementary ideals II, to appear.

6. D. Rolfsen, Knots and Links, Publish or Perish Lecture Notes Series, Box 7108 Berkeley 94707, 1976.

7. H. Seifert, On the homology invariants of knots, Quart. J. Math. Oxford, (2) 1 (1950), 23-32.

Received April 9, 1975 and in revised form May 4, 1976.

The University of British Columbia 


\section{PACIFIC JOURNAL OF MATHEMATICS}

\section{EDITORS}

RICHARD ARENS (Managing Editor)

University of California

Los Angeles, CA 90024

Charles W. Curtis

University of Oregon

Eugene, OR 97403

C. C. MOORE

University of California

Berkeley, CA 94720

\section{J. DugundJI}

Department of Mathematics

University of Southern California

Los Angeles, CA 90007

R. FinN and J. Milgram

Stanford University

Stanford, CA 94305

ASSOCIATE EDITORS
E. F. BECKENBACH
B. H. NeumanN
F. WOLF
K. YOSHIDA

\section{SUPPORTING INSTITUTIONS}

UNIVERSITY OF BRITISH COLUMBIA CALIFORNIA INSTITUTE OF TECHNOLOGY

UNIVERSITY OF CALIFORNIA

MONTANA STATE UNIVERSITY

UNIVERSITY OF NEVADA, RENO

NEW MEXICO STATE UNIVERSITY

OREGON STATE UNIVERSITY

UNIVERSITY OF OREGON

OSAKA UNIVERSITY

\author{
UNIVERSITY OF SOUTHERN CALIFORNIA \\ STANFORD UNIVERSITY \\ UNIVERSITY OF HAWAII \\ UNIVERSITY OF TOKYO \\ UNIVERSITY OF UTAH \\ WASHINGTON STATE UNIVERSITY \\ UNIVERSITY OF WASHINGTON \\ AMERICAN MATHEMATICAL SOCIETY
}

The Supporting Institutions listed above contribute to the cost of publication of this Journal, but they are not owners or publishers and have no responsibility for its content or policies.

Mathematical papers intended for publication in the Pacific Jaurnal of Mathematics should be in typed form or offset-reproduced, (not dittoed), double spaced with large margins. Please do not use built up fractions in the text of your manuscript. You may however, use them in the displayed equations. Underline Greek letters in red, German in green, and script in blue. The first paragraph or two must be capable of being used separately as a synopsis of the entire paper. Items of the bibliography should not be cited there unless absolutely necessary, in which case they must be identified by author and Journal, rather than by item number. Manuscripts, in triplicate, may be sent to any one of the editors. Please classify according to the scheme of Math. Reviews, Index to Vol. 39. All other communications should be addressed to the managing editor, or Elaine Barth, University of California, Los Angeles, California, 90024.

The Pacific Journal of Mathematics expects the author's institution to pay page charges, and reserves the right to delay publication for nonpayment of charges in case of financial emergency.

100 reprints are provided free for each article, only if page charges have been substantially paid. Additional copies may be obtained at cost in multiples of 50 .

The Pacific Journal of Mathematics is issued monthly as of January 1966. Regular subscription rate: $\$ 7200$ a year (6 Vols., 12 issues). Special rate: $\$ 36.00$ a year to individual members of supporting institutions.

Subscriptions, orders for back numbers, and changes of address should be sent to Pacific Journal of Mathematics, 103 Highland Boulevard, Berkeley, California, 94708.

PUBLISHED BY PACIFIC JOURNAL OF MATHEMATICS, A NON-PROFIT CORPORATION

Printed at Kokusai Bunken Insatsusha (International Academic Printing Co., Ltd.). 8-8, 3-chome, Takadanobaba, Shinjuku-ku, Tokyo 160, Japan.

Copyright (C) 1975 by Pacific Journal of Mathematics Manufactured and first issued in Japan 


\section{Pacific Journal of Mathematics}

\section{Vol. 71, No. $2 \quad$ December, 1977}

Krishnaswami Alladi and Paul Erdős, On an additive arithmetic

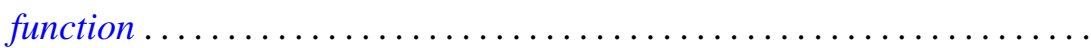

James Bailey and Dale Rolfsen, An unexpected surgery construction of a

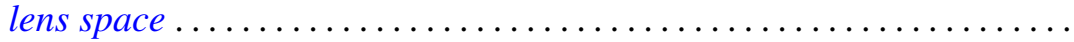

Lawrence James Brenton, On the Riemann-Roch equation for singular

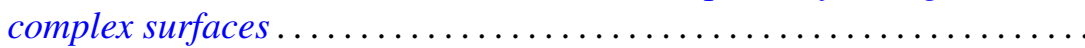

James Glenn Brookshear, Projective ideals in rings of continuous

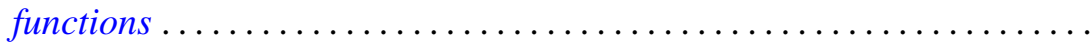

Lawrence Gerald Brown, Stable isomorphism of hereditary subalgebras of

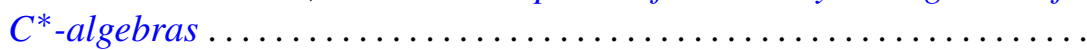

Lawrence Gerald Brown, Philip Palmer Green and Marc Aristide Rieffel, Stable isomorphism and strong Morita equivalence of $C^{*}$-algebras....

N. Burgoyne, Robert L. Griess, Jr. and Richard Lyons, Maximal subgroups

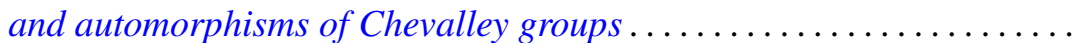
365

Yuen-Kwok Chan, Constructive foundations of potential theory .... 405

Peter Fletcher and William Lindgren, On $w \Delta$-spaces, $w \sigma$-spaces and

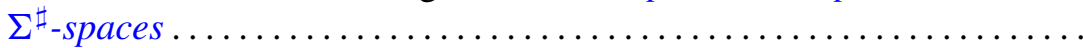

Louis M. Friedler and Dix Hayes Pettey, Inverse limits and mappings of

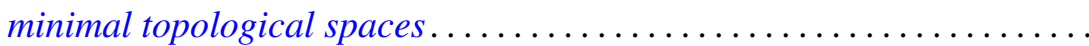

Robert E. Hartwig and Jiang Luh, A note on the group structure of unit regular ring elements.

I. Martin (Irving) Isaacs, Real representations of groups with a single involution ...

Nicolas P. Jewell, The existence of discontinuous module derivations . .

Antonio M. Lopez, The maximal right quotient semigroup of a strong semilattice of semigroups .......................

Dennis McGavran, $T^{n}$-actions on simply connected $(n+2)$-manifolds

Charles Anthony Micchelli and Allan Pinkus, Total positivity and the exact $n$-width of certain sets in $L^{1}$.

Barada K. Ray and Billy E. Rhoades, Fixed point-theorems for mappings with a contractive iterate .......................

Fred Richman and Elbert A. Walker, Ext in pre-Abelian categories. .

Raymond Craig Roan, Weak* generators of $H^{\infty}$ and $l^{1}$..

Saburou Saitoh, The exact Bergman kernel and the kernels of Szegö type...

Kung-Wei Yang, Operators invertible modulo the weakly compact 